\title{
A águia e os estorninhos Galileu e a autonomia da ciência
}

\author{
PABLO MARICONDA \\ HUGH LACEY
}

RESUMO: A idéia de que a ciência é "livre de valores" pode ser reconduzida à emergência da distinção entre fato e valor no século XVII. Pode-se considerar que essa idéia tem três componentes: imparcialidade, neutralidade e autonomia. Mostramos que partes importantes dessas idéias componentes foram desenvolvidas e defendidas por Galileu, principalmente em suas cartas a Castelli e à grã-duquesa Cristina e em seus livros O ensaiadore Diálogo sobre os dois máximos sistemas do mundo. $\mathrm{O}$ argumento de Galileu em favor da autonomia é particularmente poderoso e, embora não tenha a generalidade introduzida por argumentos posteriores (uma vez que seu principal objetivo era o de garantir a autonomia da ciência com relação à autoridade da Igreja), permanece no cerne de todas as defesas subseqüentes da autonomia da ciência. Esse argumento está baseado em três suposições: que o entendimento científico está sujeito a critérios que são independentes da autoridade da Igreja e de qualquer perspectiva de valor; que os cientistas cultivam as virtudes do "ethos científico"; e que (porque usam linguagens diferentes - o argumento dos "dois livros") não pode existir contradição entre os juízos científicos apropriados e as declarações da Igreja. Finalmente, algumas limitações dos argumentos de Galileu são indicadas, sem serem desenvolvidas.

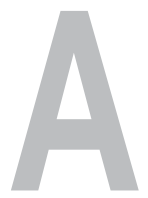

distinção entre fato e valor emerge, pela primeira vez, na cultura ocidental por ocasião da intensa polêmica causada pela recepção e defesa da teoria heliocêntrica de Copérnico. Ela comparece explicitamente articulada na polêmica teológico-cosmológica que se seguiu ao anúncio das descobertas telescópicas de Galileu no Sidereus nuncius (1610) e que antecedeu a condenação do De revolutionibus de

PALAVRAS-CHAVE: Galileu Galilei, fato, valor, ciência.
Professor do Departamento de Filosofia da FFLCH - USP

Professor titular de filosofia do Swarthmore College, Pensilvania, Estados Unidos 
Uma primeira versão deste ensaio foi apresentada na HOPOS 2000: Third International History of Philosophy of Science Conference, Viena (Áustria), julho 6-9, 2000. Uma segunda versão foi apresentada na ANPOF: IX Encontro Nacional de Filosofia, Poços de Caldas (Brasil), outubro 3-8, 2000. Os autores agradecem o apoio recebido da FAPESP.

Para uma exposição detalhada e completa deste ponto, cf. Lacey (1999, 2000).
Copérnico pela Inquisição romana, proibido pelo decreto da Sagrada Congregação do Índice de 1616.

No devido tempo, a distinção entre fato e valor serviu para embasar a concepção de que a ciência é livre de valores, a qual se manifesta em graus variados nas práticas e instituições científicas. O modo de articulação dessa concepção deriva (em parte) da reflexão sobre os modos concretos pelos quais ela se tornou manifesta no decorrer dos séculos. Ela não se manifestou concretamente nas práticas e instituições científicas sem conflito. Interesses e poderes rivais opuseram-se a ela. O modo pelo qual ela se tornou manifesta exibe assim as cicatrizes do conflito; ao mesmo tempo, seu modo de manifestação reflete também um ideal de entendimento científico e suas bases racionais. As articulações da idéia refletem, portanto, as cicatrizes do conflito e o ideal. Retornar às fontes da concepção atual de que a ciência é livre de valores pode ajudar-nos a discernir quanto das articulações contemporâneas refletem o ideal racional e quanto elas escondem de compromissos meramente históricos, enganosamente tomados como fazendo parte do ideal racional e que servem talvez para disfarçar que as investigações nas quais os cientistas se engajam atualmente podem não se conformar adequadamente ao ideal racional.

A idéia de que a ciência é livre de valores pode ser considerada ${ }^{1}$ como um valor das práticas e das instituições científicas com três componentes: imparcialidade, neutralidade e autonomia. A imparcialidade baseia-se na distinção entre os critérios para a avaliação epistêmica de teorias científicas e os valores e crenças sociais, culturais, religiosos, metafísicos e morais. A neutralidade afirma primeiro (neutralidade cognitiva) que não se podem extrair de teorias científicas conclusões no domínio dos valores; e segundo (neutralidade aplicada) que, no contexto de aplicação, uma teoria bem estabelecida serve, em princípio, aos interesses de todas as perspectivas de valores mais ou menos de igual modo. A autonomia refere-se à carência (ou ausência) de um papel legítimo para os fatores de fora (externos) (tal como valores sociais, crenças religiosas e ideológicas e o "testemunho de autores") para as práticas internas da metodologia científica, não só com relação à escolha de teorias, mas também com relação à determinação das abordagens de pesquisa. A autonomia acarreta, portanto, que as práticas científicas devem ser conduzidas livres de qualquer interferência de fora (externa) e, nas versões contemporâneas, ao mesmo tempo, que elas devem ser patrocinadas com os recursos necessários pelas várias instituições públicas e particulares tal que os cientistas possam continuar - de qualquer modo que considerem apropriado - em seu objetivo de obter e confirmar o entendimento de fenômenos do mundo, em conformidade com a imparcialidade e a neutralidade. De fora ou externa significa "não apropriada, em vista dos objetivos positivos da ciência"; entretanto, tal caracterização permanece uma tautologia vazia enquanto não forem especificadas as influências apropriadas sob a forma de princípios. As listas de interferências externas que devem ser evitadas incluem tipicamente itens tais como as opiniões religiosas, políticas ou ideológicas, popula- 
res ou apressadas (Galilei, 1928-1938, V, p. 320); as visões valorativas e seus pressupostos e certas visões metafísicas. Esta lista certamente evoca velhos conflitos. Não se teria talvez deixado de incluir certos itens simplesmente porque eles foram os aliados da ciência em seus conflitos? A metafísica materialista ou as visões matematizadas do mundo apresentam-se como possíveis candidatos, assim como os interesses que são favorecidos pelas aplicações do conhecimento científico.

Essas três componentes da idéia da ciência como livre de valores constituem uma parte fundamental do auto-entendimento da tradição da ciência moderna desde o século XVII. Nesta apresentação, focalizaremos principalmente a autonomia e especialmente a contribuição de Galileu para a análise desse componente central da concepção seiscentista da ciência. O conflito entre Galileu e a Igreja é bem conhecido como um símbolo dos caminhos trágicos que se podem tomar quando a liberdade de pesquisa científica não é respeitada: erros perpetuam-se, a pesquisa estagna, vidas e carreiras criativas são impedidas, direitos humanos são violados, o progresso do conhecimento é retardado; e, quando se consideram os conflitos famosos mais recentes (por exemplo, o caso Lysenko), pode-se acrescentar: aplicações adequadas são deixadas de lado enquanto alternativas ideologicamente inspiradas adquirem hegemonia, com conseqüências catastróficas na vida social e política. O símbolo de Galileu no conflito com a Igreja nutriu a idéia de que a ciência é ou deve ser livre de valores, permitindo que essa idéia ganhasse seu lugar como uma parte, reiteradamente afirmada e freqüentemente reinterpretada, do autoentendimento comum da tradição da ciência moderna. Mas, quando se discute a liberdade da pesquisa científica, Galileu é muito mais do que um símbolo; seus argumentos em favor da autonomia da ciência são seminais.

Galileu não considerou a autonomia da ciência em toda sua generalidade $^{2}$. Sua meta era conseguir que a investigação científica fosse livre da interferência específica da Igreja católica exercida por meio de sua autoridade no ensino, de seu sistema legal de condenações e punições, pela coerção violenta ou pela ameaça de violência e por inúmeras outras formas de tormento ${ }^{3}$. Mais especificamente, Galileu visava que as disciplinas científicas matemáticas se autonomizassem do controle da teologia escolástica e, positivamente, pretendia conquistar para os cientistas o direito de investigar, de fazer novas descobertas com liberdade de interpretação e de avaliação dos resultados, sem estarem obrigados às autoridades religiosas; e o direito de ensinar e defender suas conclusões científicas sem a restrição de ter que esperar pelas interpretações escriturais ou outras doutrinas que caíam sob a autoridade reivindicada pela Igreja. Galileu ressentia-se profundamente com a interferência constante no seu empreendimento científico (tanto das autoridades religiosas como daquelas acadêmicas que, sentindo-se confortáveis em épocas repressivas, preferiam fazer acusações ao invés de engajar-se seriamente em controvérsias científicas), não só porque seus oponentes não admirassem sua notável capacidade e extraordinária contribuição científicas, mas também porque ele os
Nesta discussão utilizamos principalmente os seguintes trabalhos de Galileu: a carta a Benedetto Castelli de 21 de dezembro de 1613; a carta à grãduquesa Cristina de Lorena de 1615; $O$ ensaiador (1623) e o Diálogo sobre os dois máximos sistemas do mundo (1632). Esses textos serão referidos em suas versões originais publicadas na Edizione Nazionale delle Opere di Galileo Galilei, usando o expediente de abreviar a referência por Galilei, 1928-1938, seguida do volume dessa edição indicado por números romanos. Para as referências completas, cf. as referências bibliográficas ao final do ensaio.

3 Galileu desejava também obter liberdade com relação às restrições da estrutura e do currículo universitários dominantes, do sistema científico aristotélico e da autoridade dos textos antigos (cf. Mariconda, 1997, 2000). 
desprezava e ridicularizava enquanto integrantes de escolas que sacrificam a liberdade da pesquisa com a submissão ao princípio de autoridade. É esse o sentido da passagem de $O$ ensaiador em que Galileu move a seguinte crítica ao padre jesuíta Orazio Grassi, que se disfarçava sob o pseudônimo de Sarsi:

Talvez acredite Sarsi que bons filósofos se encontrem em quadras inteiras e dentro de cada recinto dos muros? Eu, Senhor Sarsi, acredito que voem como as águias e não como os estorninhos. É bem verdade que aquelas, porque são raras, pouco se vêem e menos ainda se ouvem, e estes, que voam em bando, enchendo o céu de estridos e de rumores, aonde quer que pousem, emporcalham o mundo (Galilei, 19281938, VI, p. 236-237).

Este tipo de retórica era celebrado por seus aliados, mas certamente criou-lhe muitos inimigos. Contudo, essa retórica, cujo principal objetivo é "chamar a atenção", não deve obscurecer o fato de que, para Galileu, a autonomia da ciência fundamentava-se não na auto-indulgência, mas em argumentos sustentados. A estratégia de Galileu é, então, a de desenvolver um argumento tão efetivo quanto correto; ou seja, um argumento capaz de persuadir as autoridades religiosas. Qualquer argumento efetivo de que a ciência deve estar livre da interferência da Igreja não poderia permitir que o empreendimento científico estivesse sujeito a restrições por parte de setores opostos à Igreja católica. Galileu é levado, então, a argumentar que a ciência deve estar livre de todas as interferências de fora (externas) ao mesmo tempo que se obriga a retratá-la como um "valor universal", um objeto de valor para qualquer ponto de vista moral ou metafísico razoável.

O argumento de Galileu - refinado, generalizado e suplementadopermanece no centro de todas as defesas da autonomia da ciência. Para ele, podemos dizer, a autonomia é necessária porque as práticas científicas contribuem para produzir conhecimento do mundo, representado por teorias que manifestam sempre no mais alto grau a imparcialidade e a neutralidade. Podemos reconstruir o argumento de Galileu como estando baseado nas três seguintes suposições:

1) Os empreendimentos científicos possibilitam descobertas sobre os fenômenos naturais, descobertas que são feitas pelo uso dos métodos apropriados da ciência, que estão assentados principalmente em observações dos fenômenos e em inferências corretas envolvendo essas observações. As questões de valores nada têm a ver com a observação precisa ou a inferência válida. Ou seja, o método da ciência não deve responder cognitivamente às propostas e às críticas de qualquer ponto de vista valorativo (concernente a valores). Nem a Igreja, nem seus oponentes, nem qualquer ponto de vista baseado em valores têm autoridade no domínio próprio da ciência.

2) Os juízos científicos são feitos por "especialistas" - aquelas águias que voam solitárias -; cientistas com talento intelectual relevante, pratican- 
tes do método da ciência que tenham cultivado as virtudes apropriadas para devotar-se a usá-lo estritamente.

3) Os juízos científicos bem estabelecidos, isto é, aqueles obtidos usando os métodos baseados em observações e inferências corretas que envolvem essas observações, não podem contradizer nem fornecer evidências em favor de qualquer assunto no âmbito de competência da autoridade da Igreja. Podemos generalizar esta suposição: racionalmente, esses juízos não têm nenhuma implicação nos domínios da teologia, da metafísica e dos valores; não fornecem evidências ou argumentos em favor de (ou contra) qualquer ponto de vista fundamental nesses domínios, seja os da Igreja, seja os de seus oponentes.

Discutiremos agora, com algum detalhe, cada uma dessas três suposições ${ }^{4}$.

\section{A imparcialidade dos juízos científicos}

Os juízos científicos adequadamente fundamentados derivam de observações (freqüientemente auxiliadas pelo uso de instrumentos que "estendem a percepção" ou de aparatos experimentais que impõem uma interpretação teórica) e inferências corretas nas quais essas observações desempenham um papel importante. Embora Galileu procurasse articular essa idéia, não chegaria a adquirir um entendimento coerente da natureza da inferência científica. Ele fala com frequiência da ciência natural como envolvendo "experiências sensíveis e demonstrações necessárias", "razões concludentes e demonstrativas" (Galilei, 1928-1938, p. 157) e "experiências, longas observações e demonstrações necessárias” ( Galilei, 1928-1938, V, p. 330), aceitando aparentemente que a demonstração, tal como articulada nos $\mathrm{Se}$ gundos analíticos de Aristóteles e desenvolvida pelos comentadores, é a marca do conhecimento científico apropriado (cf. Wallace, 1992a, 1992b); que se caracteriza pela exigência de que, para serem aceitas, as teorias científicas devem ser demonstradas com necessidade e certeza. Essa adesão à concepção apodítica de ciência é, em parte, responsável por não ter Galileu submetido à avaliação empírica o velho princípio platônico do movimento uniforme e circular dos corpos celestes. Por outro lado, poucos argumentos científicos de Galileu podiam satisfazer esse padrão muito exigente e atingir o estatuto de certeza - talvez seu argumento de que os planetas inferiores (Mercúrio e Vênus) circundam o Sol satisfaça esse critério (pelo menos tão bem quanto os melhores argumentos aristotélicos), mas não seus argumentos em favor do sistema copernicano completo (cf. Wallace, 1992a; McMullin, 1978, 1998). Apesar disso, ao apresentar seus argumentos em favor do sistema de Copérnico, Galileu mostra geralmente uma consciência sutil de alguns dos critérios não-demonstrativos que devem informar a inferência científica correta. Para ilustrar, citaremos quatro dos critérios que Galileu emprega explicitamente nos seus argumentos.
${ }^{4}$ Cabe notar, neste ponto, que cada uma destas três suposições pode ser vista como respondendo a uma objeção levantada pelos oponentes de Galileu contra a concessão de autonomia aos cientistas e a suas práticas. Contudo, de modo a antecipar objeções ulteriores (que não fazem parte do caso Galileu), seria preciso acrescentar os seguintes itens aos três introduzidos por Galileu: 4) a condução da investigação científica, incluindo a experimental, não envolve conduta não-ética da parte do cientista. ( $\mathrm{Pa}$ rece razoável supor que Galileu teria reconhecido a autoridade da Igreja no questionamento (e proibição) de condutas não-éticas percebidas na ciência); 5) as aplicações práticas das descobertas científicas servem aos interesses da Igreja ou, pelo menos, elas não servem mais completamente aos interesses que competem com aqueles da Igreja; mais geralmente, (em princípio) os interesses de todas as visões valorativas viáveis podem ser igualmente servidos pelas aplicações científicas (Note-se que 3 não implica 5). 
I) Adequação empírica - ou seja, concordância com os fenômenos, as experiências e os experimentos observados, especialmente com os dados empíricos precisos ou quantitativamente exatos, e poder preditivo com respeito a esses dados -"acuratíssimas observações" (Galilei, 19281938, V, p. 313); "longas e acuradas observações" (Galilei, 1928-1938, V, p. 330). Note-se que Galileu enfatizava que o método científico requer investigações que aumentem o alcance dos dados relevantes e disponíveis (cf. Galilei, 1928-1938, VII, p. 299-346); que o recurso a esses dados supera o "testemunho dos escritores" (Galilei, 1928-1938, VI, p. 337) e a "autoridade de passagens das Escrituras" (Galilei, 1928-1938, V, p. 316) e torna a opinião do "vulgo" irrelevante.

II) Poder explicativo - ou seja, a capacidade de explicar os fenômenos, cuja observação serve para a obtenção dos dados empíricos; a capacidade, em suma, de identificar as causas dos fenômenos. Enquanto na tradição aristotélica a análise causal está intimamente ligada com a demonstração, Galileu, em sua prática, contentava-se com explicações que fossem melhores do que as produzidas pelas teorias rivais ${ }^{5}$. Também reconhecia que as explicações causais envolvem relações lógicas entre os dados e as suposições teóricas fundamentais, as quais são mediadas pelas várias "hipóteses auxiliares". Galileu propõe que tais mediações devem sujeitar-se ao seguinte critério:

III) Limitação do uso de "ficções" - ou seja, de hipóteses ad hoc que Galileu chamava "infelicíssimas inópias" (Galilei, 1928-1938, VII, p.

5 Galileu sustenta que Copérnico pode explicar o que Ptolomeu pode apenas descrever; que Copérnico tem poder explicativo assim como adequação empírica, enquanto Ptolomeu tem apenas esta última. Kepler complementa este argumento: Copérnico pode também explicar por que Ptolomeu, embora falso, pode ser empiricamente adequado; ou seja, Copérnico pode explicar que Ptolomeu tem algumas das características presentes em seu sistema (McMullin, 1998). Kepler está introduzindo um critério ulterior: "proporcionar o poder de interpretar outras teorias" (cf. Lacey, 1999, p. 60) 345) e "subterfúgios" (Galilei, 1928-1938, VII, p. 346) - isto é, minimização do uso de hipóteses introduzidas unicamente para manter a adequação empírica em detrimento do poder explicativo. Referindo-se a um crítico que propunha hipóteses ad hoc para opor-se às descobertas telescópicas:

\section{Parece-me que vejo aquele infeliz agricultor que, depois de ter todas as suas colheitas destruídas pela tempestade, vai com a face abatida e desolada jun- tando relíquias tão infimas, que não são suficientes para nutrir nem mesmo um pintinho por um só dia (Galilei, 1928-1938, VII, p. 346).}

Ao invés de "ficções", Galileu propunha o uso de hipóteses confirmadas (ainda que em parte) em virtude da existência de analogias experimentais (cf. Galilei, 1928-1938, VI, p. 345; VII, p. 447). O exemplo mais claro do uso de analogias experimentais por parte de Galileu pode ser encontrado na teoria das marés da Quarta Jornada do Diálogo. A analogia entre a barca carregada de água e a Terra e seus oceanos serve claramente ao propósito de fornecer uma confirmação empírica parcial da hipótese de que o fluxo e refluxo do mar é primariamente causado pelo movimento do vaso continente (cf. Galilei, 1928-1938, VII, p. 450-2; Mariconda, 1999). Assim também, a analogia entre o mecanismo de regulação dos grandes relógios de rodas e o sistema Lua-Terra, no qual a Lua funciona como contrapeso, serve ao propósito de 
fornecer uma confirmação empírica parcial para a hipótese de que o movimento da Lua em torno da Terra é responsável pelo ciclo mensal das marés (cf. Galilei, 1928-1938, VII, p. 474-6; Mariconda, 1999).

IV) Simplicidade - ou seja, preferência por teorias nas quais as partes se encaixam umas com as outras harmoniosamente com um mínimo de suposições ou com suposições mais simples (Galilei, 1928-1938, VII, p. 369; Finocchiaro, 1997, p. 327s). Uma parte importante da argumentação de Galileu em favor do sistema copernicano é produzida por uma articulação dos princípios metafísicos da perfeita ordenação e harmonia das partes do universo e da simplicidade da natureza. Por exemplo, na comparação entre o sistema de Copérnico e o sistema de Ptolomeu com vistas a mostrar que o primeiro é mais plausível que o segundo, quando se considera o movimento diurno, Galileu apóia seu argumento na maior simplicidade do primeiro sobre o segundo, porque 1) o número de corpos que se movem é maior no sistema geoestático que no sistema geocinético, ou seja, ao invés de fazer girar todos os corpos do universo, basta fazer girar somente a Terra; 2) o tamanho dos corpos em movimento é maior no primeiro do que no segundo caso, sendo evidente que a esfera das estrelas é incomensuravelmente maior do que a Terra; 3 ) as velocidades do movimento diurno são imensamente maiores no primeiro do que no segundo caso: fazer girar em 24 horas a imensa circunferência do universo ao invés de girar a pequena circunferência terrestre (cf. Galilei, 1928-1938, VII, p. 142-50). Cabe notar que a simplicidade é muitas vezes tomada como um princípio metodológico, isto é, como uma regra ou diretiva segundo a qual se deve preferir as hipóteses ou teorias mais simples, independentemente se a natureza ou os fenômenos estudados podem ser ditos simples. Seu uso apóiase, nesse caso, em considerações de ordem estética, como a "elegância matemática" da teoria, ou ainda em considerações de ordem epistemológica (psicológica), como a de maior facilidade de entendimento e de operação com uma teoria que utiliza menos hipóteses ou hipóteses matematicamente mais simples. Entretanto, em Galileu, o princípio de simplicidade recebe uma formulação que pode ser chamada de ontológica (metafísica), pois é tomado como um princípio cosmológico geral acerca das operações da própria natureza. A teoria deve ser simples, porque a natureza é simples, isto é, não faz por muitos meios o que pode fazer com poucos (cf. Galilei, 1928-1938, VII, p. 143; 149; 423). Estas breves considerações são suficientes para indicar o imbricamento que Galileu opera entre a perspectiva realista ("nós não buscamos aquilo que Deus podia fazer, mas aquilo que ele fez") e a concepção metafísica da simplicidade ("Ele tem sempre, no operar, os modos mais fáceis e simples" ou "Ele gosta da simplicidade e da facilidade"), que preside a ordenação real do mundo, a verdadeira disposição das partes do universo (Galilei, 1928-1938, VII, p. 565-6). Por outro lado, uma tal articulação da simplicidade impede evidentemente o uso de hipóteses instrumentalistas, cuja introdução visa apenas a adequação do cálculo às observações sem restrições concernentes à simplicidade da representação obtida por meio dessas hipóteses. 
${ }^{6}$ Evidentemente, empregamos a terminologia contemporânea para caracterizar os critérios como "valores cognitivos" e para atribuir-lhes os rótulos usados no texto, mas o conteúdo especificado nos quatro critérios decorre dos escritos de Galileu.

7 Note-se que não é claro que a teoria copernicana tinha um poder explicativo superior ao de suas principais predecessoras, muito embora a maior manifestação por ela revelada dos itens III e IV tenha sido vista como sugerindo uma maior manifestação de II. O argumento causal (a teoria das marés) de Galileu em favor do duplo movimento da Terra obteve pouco apoio e foi completamente descartado. Os críticos também assinalavam que a teoria de Galileu não manifestava em alto grau outro valor cognitivo importante: V) consistência com a melhor teoria física disponível. Mas é óbvio que Galileu respondia que a teoria física considerada, a saber, a filosofia natural de Aristóteles, não é nem mesmo internamente consistente.
Os quatro critérios de avaliação de teorias científicas que acabamos de apresentar podem ser tomados como valores cognitivos (cf. Lacey, 1998, cap. 3; 1999, cap. 3) ${ }^{6}$. Eles são distintos dos valores sociais e morais ou das crenças religiosas (cf. Lacey, 1999, cap. 9). Galileu mantinha que uma teoria que satisfaça bem esses critérios (valores cognitivos) é superior a outra que não os satisfaça. Mantinha que a teoria copernicana era superior neste sentido às rivais daquele tempo e, portanto, devia ser aceita. (De fato, estava enganado a esse respeito; a teoria de Kepler era superior - em parte, como conseqüência de que Kepler usou argumentos empíricos para refutar o princípio do movimento uniforme e circular dos corpos celestes.) Fica clara agora a razão pela qual Galileu não aceitava uma interpretação instrumentalista ("ficcionalista") da teoria de Copérnico. Embora carecesse de demonstração, segundo ele, a teoria copernicana era claramente superior a suas rivais com respeito à manifestação de todos os valores cognitivos citados acima ${ }^{7}$. Não obstante, Galileu fazia o tipo correto de inferência científica, a saber, o tipo de inferência que produz conclusões abertas à reavaliação à luz de observações adicionais e de novos argumentos baseados em critérios não-demonstrativos (valores cognitivos). Deste modo, Galileu antecipou detalhadamente a idéia de imparcialidade: aceitam-se as teorias se, e somente se, elas manifestam em alto grau os valores cognitivos e manifestam esses valores em graus mais elevados do que as teorias rivais (cf. Lacey, 1999, caps. 4 e 10), ainda que Galileu, diferentemente de Pascal em 1648 (cf. Pascal 1989, 1998), não distinguisse claramente entre essa aceitação de teorias e as demonstrações e, assim, não reconhecesse claramente que, quando teorias são aceitas com base nesses critérios, elas não foram demonstradas com certeza, mas permanecem (em princípio) abertas a reavaliações ulteriores.

\section{O "ethos" científico e o cultivo das "virtudes científicas"}

Para Galileu, os juízos feitos de acordo com a imparcialidade proporcionam um conhecimento superior dos fenômenos naturais à luz de critérios que não trazem a marca de compromissos religiosos ou valorativos. Esta é uma suposição essencial para seu argumento em favor da autonomia das práticas científicas; autonomia que é necessária para obter e confirmar mais conhecimentos satisfazendo o teste da imparcialidade. $\mathrm{O}$ argumento pretendia, porém, legitimar a provisão de liberdade para os pesquisadores como o próprio Galileu e Copérnico. Eles merecem a liberdade de falar e ser escutados "por pessoas entendidas e não excessivamente conturbadas pelas próprias paixões e interesses" (Galilei, 1928-1938, V, p. 285), não só em vista do objetivo afirmado de produzir juízos imparciais concernentes ao conhecimento dos fenômenos naturais, mas também porque, com cientistas como eles, pode-se esperar que o farão habitualmente; são "especialistas" (Galilei, 1928-1938, VII, p. 314 e segs.) bem formados, que cultivam certas virtudes que Finocchiaro (1997, p. 340-1) identificou como as virtudes de "espírito aberto e racional" ("open mindedness" e 
"rational mindedness"). A primeira virtude - a de possuir espírito aberto refere-se à disposição de alcançar suas conclusões desinteressadamente, sem dar preferência às suas próprias contribuições (Galilei, 1928-1938, V, p. 3445), à luz dos melhores argumentos que levam em consideração toda a evidência relevante disponível; aqueles que têm o espírito aberto tomam o cuidado de conhecer as perspectivas e os argumentos de seus oponentes e de responder, resolutamente, a seus argumentos mais fortes. A segunda virtude, a de possuir espírito racional, refere-se à atitude (e à prática) de aceitar uma teoria só depois da avaliação completa dos argumentos, pró e contra, "copelando-os e pesandoos com a balança do ensaiador" (Galilei, 1928-1938, VII, p. 157) para verificar se concordam com a imparcialidade.

Galileu sugere que o cultivo dessas virtudes confere uma "vantagem metodológica" (Finocchiaro, 1997, p. 339). Essa perspectiva pode ser claramente extraída daquilo que se pode chamar de "argumento da conversão", formulado por Galileu em duas oportunidades: a primeira, no Acerca da opinião copernicana, um texto de 1615 que permaneceria inédito; a segunda, no Diálogo sobre os dois máximos sistemas do mundo de 1632 (cf. Galilei, 1928-1938, VII, p. 153-8). Exposto sumariamente o argumento consiste em apontar para uma "assimetria da conversão": todos os defensores de Copérnico foram antes defensores de Aristóteles e Ptolomeu; nenhum defensor de Aristóteles e Ptolomeu foi antes defensor de Copérnico, ou seja, ninguém que se converteu ao copernicanismo retornou depois à posição aristotélicoptolomaica; logo, as razões em favor de Copérnico são melhores que as razões em favor de Aristóteles e Ptolomeu. Galileu conferia um peso inegável à "assimetria da conversão". Com efeito, em sua primeira versão, ele parece sugerir que o fato de existir tal assimetria proporciona uma base inegável para a aceitação da teoria de Copérnico e os consultores inquisitoriais responsáveis pela censura no processo de 1633 interpretaram a versão do Diálogo (embora ela compareça nessa obra no interior de um argumento mais amplo de Sagredo e seja formulada de modo bastante mais hipotético) desse modo, acusando-o de "apresentar como prova de verdade que os ptolomaicos passem aos copernicanos, e não ao contrário" (Galilei, 1928-1938, XIX, p. 327; Finocchiaro, 1989, p. 222; 1997, p. 149).

Ora, o fenômeno da "assimetria da conversão" é racionalmente relevante, embora não seja um fenômeno de fundamental importância. Apesar disso, ele é um fenômeno digno de explicação. Com efeito, ele pode ser explicado ou pela superioridade da teoria de Copérnico (a saber, que ela manifesta em maior grau os valores cognitivos com respeito aos dados disponíveis) ou por outros fatores (por exemplo, ignorância, oportunismo, auto-promoção ou talvez falta de respeito às autoridades apropriadas, impiedade, etc.). Em ambos os casos, o apelo à assimetria da conversão não elimina a necessidade de que Galileu mostre a superioridade racional da teoria de Copérnico. E, de fato, no Diálogo, Galileu reconhece claramente isso, pois a assimetria da conversão parece então estar embasada em outra assimetria, a saber, aquela que 
confere a "vantagem metodológica" aos copernicanos, a qual se articula em torno dos dois seguintes pontos: a) os copernicanos entendem a teoria aristotélico-ptolomaica e conhecem todas as observações e argumentos que a favorecem; mas não vice-versa (com efeito, Salviati apresenta vários fenômenos novos que Simplício toma como fornecendo apoio ulterior a Aristóteles e Ptolomeu, uma vez que eles podem ser prontamente explicados no interior dessa teoria); b) os copernicanos estão familiarizados com a evidência e os argumentos que contrariam Aristóteles e Ptolomeu, assim como com os argumentos levantados por estes últimos contra sua teoria; mas em ambos os casos os aristotélico-ptolomaicos estão bem menos familiarizados e, em alguns itens, são completamente ignorantes.

Isto posto, são os copernicanos e não os defensores de Aristóteles e Ptolomeu que estão melhor colocados para fazer as avaliações comparativas da evidência e dos argumentos a favor e contra os dois lados. Segundo Galileu, os copernicanos mostram que os argumentos em favor de sua teoria são muito mais convincentes do que aqueles em favor de seus oponentes e que os argumentos contra seus oponentes são devastadores; mas o importante é que os defensores da teoria oposta não estão dispostos numa perspectiva metodológica apropriada para responder ao desafio. Além disso, Galileu sugere claramente que qualquer pessoa que assuma a perspectiva metodológica do copernicanismo (ou seja, familiaridade com os dois lados) chegará ao mesmo juízo (evidentemente, ele sugere que em nenhum caso se chegou seriamente a um juízo contrário) - e é, por isso, que se chega à assimetria da conversão.

Resumindo, na controvérsia sobre a teoria de Copérnico, fica claro que os seguidores deste último, tal como Galileu, tinham conquistado a vantagem metodológica - inicialmente a maioria deles era de seguidores de Aristóteles e Ptolomeu; converteram-se quando foram "movidos pela força das razões" (Galilei, 1928-1938, VII, p. 153) - de modo que passaram a ter familiaridade com os dois lados da controvérsia (inclusive com os melhores argumentos contra Copérnico). Em contraste, ninguém - depois de ter vindo a conhecer os detalhes dos argumentos favoráveis a Copérnico - converteu-se ao outro lado. Entre os oponentes de Copérnico, "aqueles que à incredulidade (nas descobertas de Galileu) acrescentavam algum sentimento alterado" (Galilei, 1928-1938, V, p. 310), ao invés das virtudes de espírito aberto e racional, encontramos ignorância (isto é, resistência em apreender os argumentos copernicanos), tendência a recorrer dogmaticamente a autores antigos (cf. Galilei, 1928-1938, VI, p. 340-4), oportunismo e servilidade, onde não encontramos "senão sofismas, paralogismos e falácias" (Galilei, 1928-1938, V, p. 285), apelo a "aparências enganadoras, paralogismos e falácias" (Galilei, 1928-1938, V, p. 342), disposição de "abandonar totalmente os sentidos e as razões demonstrativas" (Galilei, 1928-1938, V, p. 313) e imposição de passagens escriturais mal compreendidas (Galilei, 19281938, V, p. 309) como ameaças com o propósito de dar por terminada a investigação (Galilei, 1928-1938, V, p. 311). Lembre-se aqui da metáfora 
da águia e dos estorninhos: "voar como as águias" é uma evidente expressão da independência do juízo científico caracterizada pelas virtudes de "espírito aberto e racional", cuja conseqüência é que os cientistas não podem pertencer a uma escola ("não são como os estorninhos" que voam em bando), submetendo-se ao princípio de autoridade.

Uma águia, mas não um bando de estorninhos, merece autonomia. $\mathrm{O}$ argumento em favor da autonomia supõe, portanto, que os cientistas se tenham tornado participantes do "ethos da ciência" (cf. Cupani, 1998). A certificação formal (institucional) de competência não é suficiente para legitimar a autonomia, porque os cientistas qualificados podem subordinar os seus juízos a interesses de fora (externos). Ninguém tem condições de saber o que Galileu teria achado dos fatos contemporâneos: de que certos cientistas qualificados participam em pesquisas controladas por autoridades militares ("classified research" - "pesquisa qualificada"); de que certas pesquisas se subordinam a interesses empresariais; e de que, em geral, as instituições da ciência ajustam-se a esses fatos. Poremos de lado a especulação sobre esse assunto. Basta, para nossos propósitos, lembrar que o argumento de Galileu em favor da autonomia depende dos cientistas quererem fazer juízos imparciais e cultivarem as virtudes geralmente necessárias para assegurar seu sucesso.

\section{O argumento dos "dois livros"}

De acordo com Galileu, apesar das muitas aparências em contrário, seria impossível ocorrer um conflito epistêmico real entre os resultados científicos bem estabelecidos e as verdades religiosas (inclusive escriturais). A verdade, que é tomada por Galileu como sendo uma só, aponta para uma harmonia mútua, mas não para uma subordinação de um domínio ao outro.

Sempre que um resultado científico e uma passagem das Escrituras parecem estar em conflito, essa aparência de conflito sempre pode ser removida por meio de reinterpretações apropriadas: ou o juízo científico foi inadequadamente confirmado ("demonstrado") ou a passagem escritural foi incorretamente interpretada. Até aqui, tanto Galileu quanto Bellarmino concordavam. Mas uma tensão profunda subsistia: Galileu e Bellarmino discordavam acerca de qual das alternativas devia ser aceita na questão do movimento do Sol. Bellarmino identificava "confirmação adequada" com "demonstração" e a teoria copernicana claramente não satisfazia, nem podia satisfazer, esse critério - e tampouco as teorias de Ptolomeu e Tycho Brahe. Apesar disso, Bellarmino concordava que a interpretação correta da Escritura devia ser consistente com as verdades demonstradas. A unidade da verdade impunha issomas a consistência era exigida somente para as verdades demonstradas. Para Bellarmino, se o melhor resultado científico disponível não estava demonstrado - vale dizer, se não demonstrava a impossibilidade da posição contrária devia ser entendido sob uma interpretação "instrumentalista", a saber, como uma ficção conveniente que permite o cálculo e a predição. Entretanto, as 
8 Estas questões são detalhadamente discutidas por McMullin (1998) e Finocchiaro (1980). Obviamente, toda essa discussão depende dos diferentes sentidos que são atribuídos à noção de "hipótese": ficção ou conjectura provável. Pascal (1989, 1998) revela uma excelente apreensão do caráter probabilístico da inferência científica. ficções não têm jurisdição quanto à correção da interpretação escritural. Existe um "caminho intermediário" entre a demonstração e a ficção - a saber, o da conclusão "provável", avaliada à luz dos critérios não demonstrativos, discutidos acima - que foi bem desenvolvida por Pascal quinze anos após o julgamento de Galileu. Entretanto, quando consideramos as afirmações de Galileu acerca das "demonstrações" e dos critérios que ele efetivamente costumava empregar em favor da teoria de Copérnico, podemos perceber que ele se debatia para identificar esse caminho intermediário. Apesar disso, Galileu não foi capaz de identificá-lo e Bellarmino nunca considerou seu possível impacto na interpretação escritural ${ }^{8}$.

Em vista disso, Galileu introduziu uma nova maneira de explicar por que (supostamente) os resultados científicos não podem contradizer as verdades teológicas. Segundo essa nova maneira, as questões de demonstração e probabilidade tornam-se geralmente irrelevantes, porque o que é agora importante perguntar a respeito de qualquer enunciado - usando sua metáfora sugestiva - é em qual livro está escrito: no livro da natureza ou no livro da revelação? (cf. Blackwell, 1991). Esses livros, ambos de autoria divina, são escritos em linguagens diferentes. Usando (em grau significativo) categorias incomensuráveis, os livros servem a fins diferentes e precisam ser "lidos" de maneira diferente; não podem ser traduzidos um ao outro. Portanto, nunca poderiam contradizer-se.

\section{A filosofia está escrita neste grandíssimo livro que continuamente nos está aberto diante dos olhos (eu digo o universo), mas não se pode entender se pri- meiro não se aprende a entender a língua e conhecer os caracteres, com os quais está escrito. Ele está es- crito em língua matemática, e os caracteres são tri- ângulos, círculos e outras figuras geométricas, mei- os sem os quais é impossível entender humanamente qualquer palavra; sem estes vaga-se em vão por um escuro labirinto (Galilei, 1928-1938, VI, p. 232).}

A linguagem da ciência - a do livro do universo - é matemática, rigorosa e exata. A Bíblia - o livro da revelação - está escrita em linguagem ordinária, aberta ao entendimento comum dos homens (dos leigos), descrevendo aparências e experiências, algumas vezes ambíguas e imprecisas, freqüentemente metafóricas. Há duas linguagens; não dois mundos distintos ou dois domínios distintos de fenômenos: duas linguagens que freqüentemente se aplicam aos mesmos fenômenos; mas, quando ambas se aplicam, refletem interesses distintos. Quando as pessoas comuns dizem que o Sol se move pelos céus, descrevem o que observam sem tentar explicá-lo; não se perguntam se, realmente, é o Sol ou a Terra que está em movimento e, independentemente da resposta "correta", o que é visto (percebido) permanece o mesmo. Ambas as linguagens podem ser usadas para descrever "os fatos"; a aceitação científica da teoria copernicana não contradiz o relatório observacional comum de que o Sol se move 
pelo céu de leste para oeste. A Bíblia emprega a linguagem comum, corriqueira, para relacionar os fenômenos à história sagrada da salvação (por exemplo, na famosa passagem de Josué e a parada do Sol) ou às vidas espirituais dos crentes (por exemplo, em passagens dos Salmos acerca do movimento do Sol pelos céus); e, por isso, não discorre sobre as questões científicas (por exemplo, sobre as explicações de fenômenos comumente observados tal como o movimento do Sol). Assim, não há necessidade alguma pela qual a Igreja tenha que considerar a questão copernicana em deliberações sobre a interpretação da Bíblia. Por outro lado, para Galileu, a atividade científica e suas descobertas, embora não contribuam para iluminar o sentido da história da salvação, não discordam com qualquer verdade relevante para a salvação humana que dependa, assim, da autoridade da Igreja9 .

O argumento dos "dois livros" pressupõe que os juízos científicos bem feitos concordam com a imparcialidade, isto é, que os critérios interpretativos do livro da natureza são distintos daqueles da Bíblia e que os juízos científicos são efetivamente feitos de acordo com os métodos próprios da ciência sem nenhuma restrição de fatores de fora (externos). O caráter técnico da linguagem da ciência é importante aqui; matemática, exata, abstrata: portanto (generalizando de tal modo que se aplique mais diretamente ao contexto das teorias científicas contemporâneas), a linguagem é adequada para representar a lei, a estrutura, a interação e o processo subjacentes dos fenômenos naturais. Assim, a linguagem da ciência não contém nem as categorias de valor nem outras categorias implicadas na experiência humana e nas relações sociais. A linguagem exigida pela ciência não pode, portanto, ser empregada normalmente na comunicação comum e carece dos aspectos necessários para o discurso teológico ${ }^{10}$.

O argumento dos "dois livros" é facilmente generalizado: uma vez que a linguagem da ciência carece das características exigidas por qualquer discurso sobre os valores, as teorias científicas não podem ter nenhuma implicação lógica no domínio dos valores - isto é, a ciência é cognitivamente neutra no domínio de valores ${ }^{11}$. Assim, o argumento dos "dois livros" generaliza-se no argumento dos "discursos múltiplos": o discurso da ciência e os vários discursos dos valores, onde o discurso da ciência é incomensurável com todos aqueles referentes a valores; e assim, as teorias científicas não podem servir de base para favorecer um discurso ao invés de outros. A ciência não pode resolver as grandes controvérsias com respeito aos valores. Seguese, portanto, que a autonomia pressupõe a imparcialidade e a neutralidade cognitiva e que, de fato, a atividade científica é conduzida pelos cientistas que cultivaram o "ethos" científico. Ao mesmo tempo, o argumento de Galileu em favor da autonomia implica o reconhecimento de uma certa autonomia de outros discursos, os discursos de valor e o discurso teológico ${ }^{12}$.

Independentemente do poder de persuasão dos argumentos dos “dois livros" e dos "discursos múltiplos" para os filósofos e teólogos, eles enfrentam dificuldades. Com efeito, o argumento dos “dois livros" pressupõe:
9 Galileu desenvolve detalhadamente este argumento em suas cartas a Castelli e à grãduquesa Cristina; ele é estudado e elaborado por Blackwell (1991).

${ }^{10} \mathrm{O}$ argumento dos "dois livros" é um argumento tanto filosófico como (em parte) teológico. Ele envolve uma concepção da interpretação das Escrituras. Essa concepção exegética, diferentemente dos resultados da ciência galileana, pode conflitar com as concepções acerca das quais a Igreja reivindica a autoridade - e alguém que adira aos argumentos de Galileu pode ser conduzido a interpretações escriturais que conflitam com as interpretações "autorizadas". Além disso, a concepção de Galileu é compatível com a idéia de que uma descoberta científica pode ser a ocasião para reconhecer a necessidade de reinterpretar uma passagem escritural. ( $\mathrm{O}$ conflito não é entre o resultado científico e a passagem em si, mas entre o resultado e a interpretação incorreta da passagem). Ela é também compatível com o compromisso com uma concepção teológica que proporciona a ocasião de uma nova avaliação da evidência exigida por um resultado científico. (As genera- 
lizações destas considerações para o contexto do argumento dos "discursos múltiplos" são óbvias.)

${ }^{11}$ Isto é compatível com a idéia de que a linguagem valorativa ordinária pode ser desdobrada para descrever fatos; na ciência, afastamo-nos dessa linguagem ordinária.

${ }^{12}$ No século XVII, o argumento dos "dois livros" não era a única alternativa à posição de Bellarmino. Outros (principalmente protestantes) exploraram as interpretações teológicas e as implicações dos resultados científicos - a ciência e a religião interagiam profundamente; conflitos, por exemplo, acerca da natureza de Deus faziam parte de disputas científicas (por exemplo, a disputa entre Newton e Leibniz sobre o espaço e o tempo). Esta opção tornou-se novamente corrente nas discussões recentes sobre a suposta significação teológica das teorias cosmológicas, embora a corrente principal do pensamento católico tenda a desenvolver o argumento dos "dois livros". Pode-se supor que seu correlato nos "discursos múltiplos" encontra-se na ética evolucionista: derivar valores a partir de resultados científicos. De qualquer modo, o a) que os juízos científicos são normalmente feitos de acordo com a imparcialidade; $\mathrm{e}$

b) que a linguagem da ciência é "matemática" ou "técnica" (ou, pelo menos, uma linguagem que não contém categorias valorativas ou outras categorias, cuja aplicação não envolve a abstração da experiência humana e das relações sociais); uma linguagem, em suma, capaz de representar os fenômenos em termos de hipóteses, da lei, da estrutura, da interação e do processo subjacentes.

É a linguagem técnica, não sua concordância com a imparcialidade, que assegura serem as teorias científicas cognitivamente neutras. Mas a neutralidade cognitiva não implica o outro tipo de neutralidade, a neutralidade aplicada: em princípio, os interesses de todos os pontos de vista de valor razoáveis poderiam ser igualmente satisfeitos por aplicações científicas. Lacey (1998, cap. 5; 1999, caps. 6 e 10) argumentou que, na aplicação, as teorias formuladas na linguagem "matemática" ou técnica favorecem especialmente aquelas perspectivas de valor que contêm atitudes especificamente modernas com respeito ao controle dos objetos naturais - ou seja, podem ser mais prontamente aplicadas para servir aos interesses ligados ao controle de objetos naturais, entendendo o controle como um valor não subordinado sistematicamente a outros valores sociais.

Tais atitudes com respeito ao controle estão, porém, em tensão (entre outras) com a perspectiva de valor favorecida pela Igreja católica. (Isto é particularmente óbvio hoje em conexão com o desenvolvimento da tecnologia médica.) Mas, sem a neutralidade aplicada, o argumento em favor da autonomia perde a desejada força universal. Galileu não discutiu esses assuntos ligados à aplicação do conhecimento científico, mas, atualmente, não podemos separar o empreendimento científico de suas aplicações; e já no séc. XVII, Bacon identificara o papel central das aplicações na prática científica e a sua relação com as atitudes modernas a respeito do controle dos objetos naturais. Assim, na reflexão sobre a autonomia, é preciso salientar não só a ausência de interferências externas, mas também a disponibilidade de recursos materiais e sociais necessários para o engajamento na pesquisa científica. A ausência de neutralidade aplicada não fornece razão nem para interferir nos conteúdos dos resultados científicos, nem para impor-lhes restrições; mas aqueles, cujos interesses não fossem bem servidos, poderiam questionar o valor de patrocinar a pesquisa supostamente "autônoma" que efetivamente produz resultados sem manifestar a neutralidade aplicada.

Levanta-se desse modo a seguinte questão: por que aceitar que a linguagem da teoria deve ser "matemática" ou "técnica"? Uma resposta possível seria: porque funciona; porque produz resultados! Mas este fato sustenta apenas a autonomia limitada àqueles domínios da investigação dentro dos quais poderíamos esperar que a neutralidade aplicada se manifestasse. Além disso, não implica que poderíamos obter resultados apenas desse modo. Outra resposta, afirmada freqüentemente por toda a tradição da ciência moderna, é que essa linguagem reflete o mundo tal como 
ele realmente é - a lei, a estrutura, a interação e o processo subjacentes do mundo são completamente matemáticos em todos os detalhes. Trata-se evidentemente de uma resposta metafísica. Galileu aludiu a ela; Descartes desenvolveu-a em detalhe. Ambos empregaram o artifício do dualismo (mente/corpo) para excluir do âmbito da análise matemática fenômenos humanos importantes. A matéria (a natureza) é matemática; a mente (a natureza humana) não é. Observe-se que esta resposta metafísica não depende da suposição de imparcialidade e também que a imparcialidade não pressupõe e não implica a aceitação de qualquer perspectiva metafísica.

Os juízos imparciais podem ser feitos de muitas formas, não só no discurso "matemático" - isso é de grande importância nas ciências humanas! Além disso, a tese de que a natureza (abstraída da mente) é de caráter profundamente matemático não representa um resultado científico aceito de acordo com a imparcialidade. Trata-se de uma restrição imposta sobre as teorias permitidas na investigação científica - e é uma restrição de origem metafísica. É certo que existem contradições entre essa metafísica e as pressuposições da teologia católica - note-se: contradição entre a metafísica e a teologia, mas não entre a teologia e os resultados científicos aceitos de acordo com a imparcialidade. Além disso, a tese não é absolutamente verdadeira. Cabe lembrar que Galileu mesmo faz Simplício dizer:

(essas) sutilezas matemáticas são verdadeiras em abstrato, mas aplicadas à matéria sensível e física não funcionam (...), quando se chega à matéria, as coisas vão em outra direção (Galilei, 1928-1938, VII, p. 229).

O questionamento de Simplício expressa uma preocupação séria: o sucesso de Galileu em explicar um âmbito de fenômenos interessantes com um léxico matemático não é suficiente para fundamentar a metafísica ${ }^{13}$. Pode-se sugerir (cf. Lacey, 1999, cap. 6) que a aceitação da concepção da natureza "escrita na linguagem da matemática" está fortemente vinculada a compromissos com formas modernas de valorar o controle da natureza. Se é assim, a aquisição de autonomia com relação à autoridade da Igreja estaria acompanhada por uma nova subordinação da ciência às ideologias e aos poderes modernos.

Visto desse modo, o argumento dos "dois livros" equivale a uma defesa da autonomia da ciência com relação à religião, mas não com relação às restrições metafísicas. Sem um argumento convincente pela metafísica, este não é um argumento adequado em favor da liberdade da ciência com relação a todas as interferências de fora (externas) - mesmo que a restrição metafísica seja autoimposta pelos próprios cientistas e não imposta por poderes externos. Os argumentos ulteriores em favor da autonomia da ciência não obtiveram sucesso em superar essa limitação do argumento de Galileu (cf. Lacey, 1999, cap. 10). apelo superior dos "dois livros" sobre a posição de Bellarmino é claro; no mínimo, ele expressa um compromisso que pode manter a paz por um longo período.

${ }^{13}$ Isso é ainda mais claro quando a metafísica galileana é utilizada como restrição na investigação da psicologia humana. Para uma crítica detalhada do argumento dos "dois livros" em especial com relação a esse ponto, cf. Lacey (2001). 
KEY WORDS: Galileu Galilei, facts, values, science.
MARICONDA, Pablo \& LACEY, Hugh. The eagle and the starlings - Galileo and the autonomy of science. Tempo Social; Rev. Sociol. USP, S. Paulo, 13(1): 49-65, May 2001.

ABSTRACT: The idea that science is "value free" can be traced back to the emergence of the distinction between fact and value in the 17th century. It can be considered to have three components: impartiality, neutrality and autonomy. We show that important parts of these component ideas were developed and defended by Galileo, principally in his letters to Castelli and to Grand Duchess Cristina and in his books The Assayer and Two Chief World Systems. Galileo's argument for autonomy is particularly powerful and, although lacking the generality introduced in later arguments (since his principal concern was to win autonomy for science from the authority of the Church), it remains at the core of all subsequent defenses of the autonomy of science. This argument is based on three suppositions: that scientific understanding is subject to criteria that are independent of the Church's authority and of any value perspective, that scientists have cultivated the virtues of the "scientific ethos", and that (because they use different languages — the "two books" argument) there cannot be contradiction between properly made scientific judgments and declarations of the Church. Finally some limitations of Galileo's arguments are indicated but not developed.

\section{REFERÊNCIASBIBUOGRÁFICAS}

Blackwell, R. J. (1991) Galileo, Bellarmine, and the Bible. Notre Dame, University of Notre Dame Press.

Cupani, A. (1998) A propósito do 'ethos' da ciência. Episteme, 3: 16-38.

FinocChiaro, M. A. (1980) Galileo and the art of reasoning: rhetorical foundations of logic and scientific method. Dordrecht, Reidel.

(1989) The Galileo affair: a documentary history. Berkeley, University of California Press.

(org.).(1997) Galileo on the world systems. Berkeley, University of California Press.

GALILEI, G. (1928-1938) Edizione nazionale delle opere di Galileo Galilei. In: Favaro, Antonio (org.). Edizione nazionale delle opere di Galileo Galilei. 19 vols. Florença, Barbéra.

LACEY, H. (1998) Valores e atividade científica. São Paulo, Discurso Editorial.

(1999) Is science value free? Values and scientific understanding. Londres, Routledge.

(2000) As formas nas quais as ciências são e não são livres de valores. Revista do Departamento de Filosofia da Universidade Estadual de Londrina, Londrina (no prelo). 
. (2001) Ciência e valores: como devem os valores influenciar a ciência? In: A pesquisa e novas paradigmas da sociedade: II conferência científica da Universidade Federal do Rio Grande do Sul, Porto Alegre, Editora da UFRGS (no prelo).

Mariconda, P. R. (1997) A questão da autonomia da ciência em Galileu. Conferência proferida no II Encontro de Estudos Filosóficos do Século XVII. São Paulo, 26 de maio.

. (1999) Galileu e a teoria das marés. Cadernos de História e Filosofia da Ciência, Série 3, 9(1-2): 33-71.

. (2000) O Diálogo de Galileu e a condenação. Cadernos de História e Filosofia da Ciência, Série 3, 10(1): 77-163.

McMullin, E. (1978) The conception of science in Galileo's works. In: ButTs, R. E. \& PitT, J. C. (orgs.). New perspectives on Galileo. Dordrecht, Reidel, p. 209-257.

(1998) Galileo on science and Scripture. In: MAchamer, P. (org.). The Cambridge companion to Galileo. Cambridge, Cambridge University Press, p. 271-347.

Nascimento, C. A. R. do. (1988) Ciência e fé. Cartas de Galileu sobre a questão religiosa. São Paulo, Nova Stella/Instituto Cultural ÍtaloBrasileiro.

Pascal, B. (1989) Preface to the treatise on the vacuum. In: Popkin, R. H. (org.). Pascal selections. New York, Macmillan.

. (1998) Préface sur le traité du vide. In: Guernm M. Le (org.). Oeuvres complètes. Paris, Gallimard, p. 452-458.

Wallace, W. A. (1992a) Galileo's logic of discovery and proof: The background, content and use of his apropriated treatises of Aristotle's Posterior Analytics. Dordrecht, Kluwer.

(1992b) Galileo's Logical Treatises: A translation, with notes and commentary, of his apropriated latin questions on Aristotle's Posterior Analytics. Dordrecht, Kluwer. 